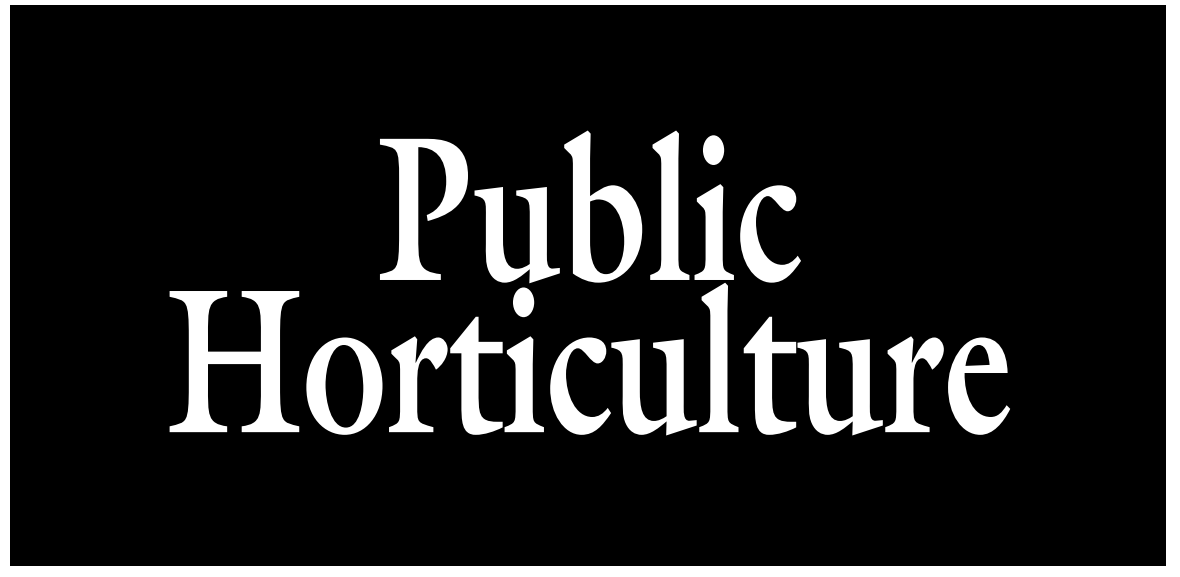

\title{
Current Status of Children's Gardens Within Public Gardens in the United States
}

\author{
Min Hyeong Kwon ${ }^{1}$, Changwan $\mathrm{Seo}^{2}$, Jongyun $\mathrm{Kim}^{3}$, \\ Moonil Kim ${ }^{4}$, Chun Ho Pak ${ }^{1}$, and Woo-Kyun Lee ${ }^{4,5}$
}

\begin{abstract}
ADDITIONAL INDEX WORDS. education, environmental experiences, community garden, school garden, GIS

SUMMARY. The purpose of this study was to identify the current status and future development of children's gardens within public gardens in the United States and to examine their roles as places for children to explore natural environments. This study identified 776 public gardens and examined 163 of those gardens using a comprehensive online survey. The sampled public gardens were widely distributed throughout the United States, although they were located primarily in the eastern and western regions of the United States. We found that $55 \%$ of the 163 public gardens that we investigated included a children's garden at the time of data collection, and $26.4 \%$ planned to add a children's garden in the near future. Children's gardens found within public gardens were typically in a botanical garden and were added after the public gardens were formed. Most of the children's gardens had a stated purpose of providing children with environmental education by allowing them to experience the natural environment through play. Most children's gardens occupied a small proportion, less than 1 acre, of the overall size of a public garden. We also found that demographic and socioeconomic factors influenced the development of children's gardens within public gardens and public gardens in general.
\end{abstract}

$\mathrm{M}$ ost people around the world today live in urban areas and spend most of their time in urban spaces. The urban population in the United States was approximately $10.8 \%$ before the Industrial Revolution began in 1840 , but it increased to $80.7 \%$ by 2010 (U.S. Census Bureau, $1990,2010)$. The United Nations reports that $54 \%$ of the world's population now lives in urban areas, and this number is expected to increase (United Nations, 2014).

Rapid industrialization and urbanization have produced a phenomenon in which contemporary citizens are living increasingly farther from nature (Nabhan and Trimble, 1994).
This phenomenon is referred to as "nature deficit," and the related disorder has resulted not only in mental problems such as depression or stress and physical health problems such as cardio-cerebrovascular disease, heart disease, diabetes, colorectal cancer, and osteoporosis but also in environmental pollution and climatic change in urban areas (Halverson et al., 2008; Lee and Maheswaran, 2011; Louv, 2008; McMichael, 2001).
As the issue of nature deficiency in urban areas has become more prominent, people have become interested in green spaces and access to natural environments. Urban public gardens provide environmental benefits to the natural ecosystem that bridge the natural environment with urban areas to reduce stress and produce a restorative effect on people (Cooper-Marcus and Barnes, 1995; Kaplan and Kaplan, 1989; Lewis, 1996; Rakow, 2011; Ulrich, 1999). Moreover, urban public gardens resolve social problems in urban society by offering a variety of educational opportunities and social gathering spots (Goddard et al., 2010; Lewis, 1992; Robertson, 1996; Sherer, 2006; Waliczek et al., 2000).

Public gardens are considered leisure destinations like museums, parks, or zoos. According to a 2011 report about the leisure market in the United States, gardening was included among the top 10 leisure activities (Falk, 1998; Leisure Market Research Handbook, 2012), and the increase of gardening as a leisure activity has been associated with the increased numbers of visitors to public gardens (Connell, 2004, 2005). According to research on children's preferences for leisure activities, however, children tend to prefer indoor activities, such as watching TV, reading, using a computer, playing video games or using other modern media (Cherney and London, 2006; Moore and Wong, 1997; Stenvall, 2009). The phenomenon in which children have more time to adapt to indoor lifestyles that are distant from natural environments has exacerbated health problems such as childhood obesity, asthma, attention deficit/hyperactivity disorder, and atopic dermatitis resulting from vitamin $\mathrm{D}$ deficiency (Mithal et al., 2009; Moore and Wong, 1997; Perrin et al., 2007; Taylor et al., 2001; Taylor and Kuo, 2009).

Because greater numbers of problems are arising for children who have less time to experience natural environments, environmental education researchers in the United States have been studying children's gardens as places where children can improve

\begin{tabular}{llll}
\hline $\begin{array}{l}\text { Units } \\
\begin{array}{l}\text { To convert U.S. to SI, } \\
\text { multiply by }\end{array}\end{array}$ & U.S. unit & SI unit & $\begin{array}{l}\text { To convert SI to U.S., } \\
\text { multiply by }\end{array}$ \\
\hline 0.4047 & acre(s) & ha & 2.4711 \\
1.6093 & $\operatorname{mile(s)}$ & $\mathrm{km}$ & 0.6214
\end{tabular}


A

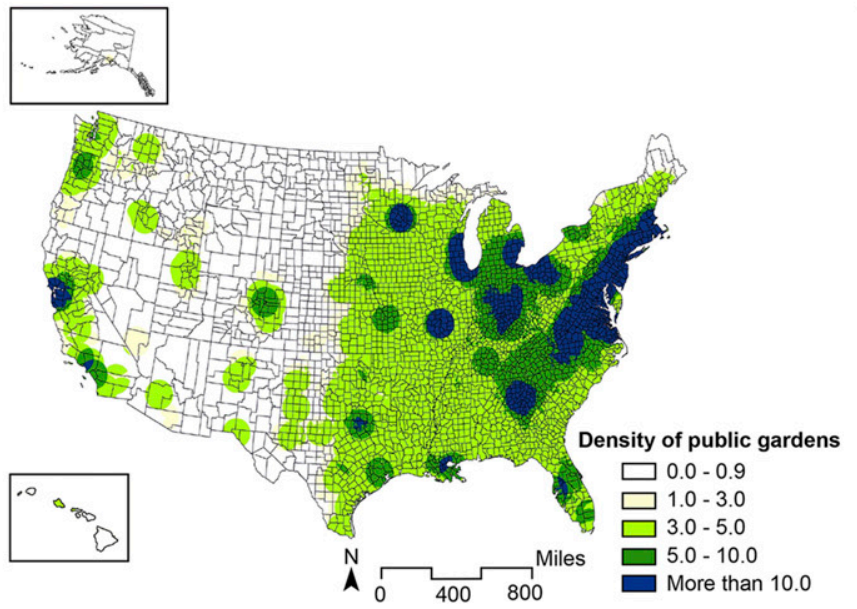

B

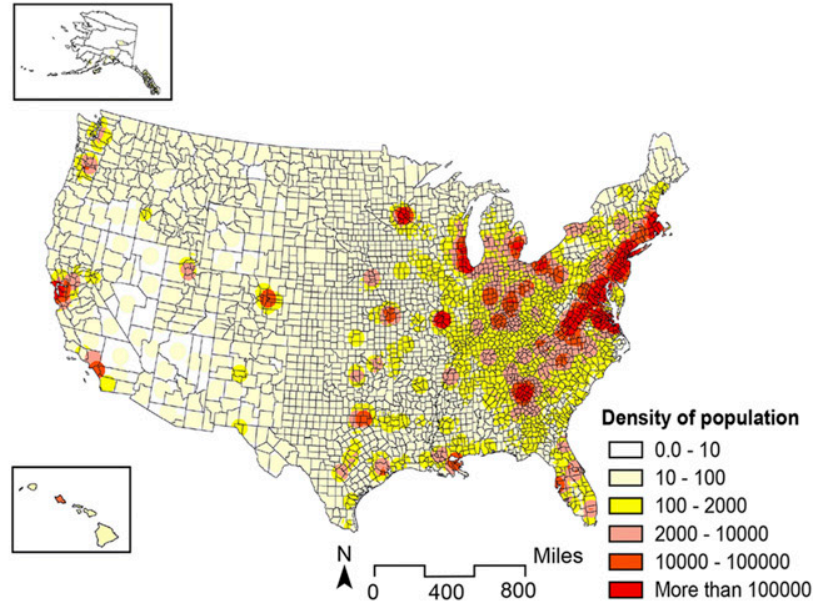

Fig. 1. (A) Density of public gardens and (B) density of county population in the United States; 1 mile $=1.6093 \mathrm{~km}$.

their physical and mental health and sociability through the pleasure and play they experience in a natural environment encountered within a city (Halverson et al., 2008; Miller, 2005; Tai, 2006; Taylor, 1994).

Children's gardens that are within public gardens and are equipped with opportunities for activities such as rest, leisure, and education have now been firmly positioned as alternative spaces that can help children become aware of natural environments. These spaces intrigue children at the appropriate level and aid in relieving various juvenile social problems resulting from naturedeficit disorder. Children's gardens are places that all family members can engage and enjoy regardless of age [American Horticultural Society (AHS), 2005; Maller and Townsend 2006; Taylor, 1994]. Additional research on family leisure activities has

We would like to express our special thanks to Dr. Chiwon W. Lee, Department of Plant Sciences, North Dakota State University, for his help in organizing, writing, editing, and proof-reading of this manuscript. Without his advice, encouragement, and many hours of work, this manuscript could not have been possible. We also thank Yun Ho Jung, a graduate student at Korea University, for technical support.

${ }^{1}$ Department of Biosystems and Biotechnology, Korea University, Seoul 136-713, South Korea

${ }^{2}$ Department of Climate and Ecology, National Institute of Ecology, Seocheon-gun, 325-813, South Korea

${ }^{3}$ Division of Biotechnology, Korea University, Seoul 136-713, South Korea

${ }^{4}$ Department of Environmental Science and Ecological Engineering, Korea University, Seoul 136-713, South Korea

${ }^{5}$ Corresponding author. E-mail: leewk@korea.ac.kr. reported that family-oriented leisure activities enhance family bonds and healthy relationships. The selection of leisure activities by young children is influenced by their parents (Hawks, 1991; Holder et al., 2009; Shaw and Dawn, 2001). Therefore, children's gardens within public gardens not only allow for the rest, leisure, and education of children, but they also benefit the families who visit them.

The first children's garden established in a public garden in the United States was the Brooklyn Botanic Garden, which was built in New York in 1914 to help educate children about gardening (Shair, 1999). With this garden as an exemplary case, children's gardens began to gradually spread throughout the United States (Stone, 1984; Trelstad, 1997). In 1993, the Michigan 4-H Children's Garden was established at Michigan State University in East Lansing to teach children about the importance of plants, to induce curiosity, and to provide experiences of aesthetic richness while including many educational elements (Sobaski, 2006).

As the importance and popularity of children's gardens has increased, many studies have emerged about the design elements of children's gardens (DiMare, 2012; Eberbach, 1988; Miller, 2005, 2010; Sobaski, 2006) as well as the importance of spaces for environmental education (Halverson et al., 2008; Hoffman, 2008; Tai, 2006) and spaces for the mental and physical development of children (Maller and Townsend, 2006; Pretty et al., 2005). However, little research has been conducted using quantitative data or analyses that show the overall distribution and status of children's gardens within public gardens in the United States.

Accordingly, this study was designed to examine the distribution of children's gardens within public gardens, to understand their presence, and to determine the demographic and socioeconomic factors that affect the development of children's gardens with the overall goal of illustrating the status and future development of children's gardens.

\section{Materials and methods}

Study Design. The study was conducted from Jan. 2010 to Aug. 2014. To examine the distribution and status of children's gardens situated within public gardens in the United States, a list of public gardens in the 50 states and Washington, DC, was compiled using a total of 12 sources, including six official garden-related institutes, two private informational websites, two Internet search engines, and two children's garden-related literature resources. The six official gardenrelated institutes included the AHS (2010), the American Public Gardens Association (2010), Botanic Gardens Conservation International (BGCI, 2010), the Children's Garden Network (CGN, 2011), The Morton Register of Arboreta (MRA, 2011), and the National Gardening Association (NGA, 2010). The two private informational websites included The Garden and Landscape Guide, Nightingale Garden Company Limited 
Table 1. Distribution of children's gardens by state, as compiled from online surveys and lists of U.S. public gardens from 12 sources.

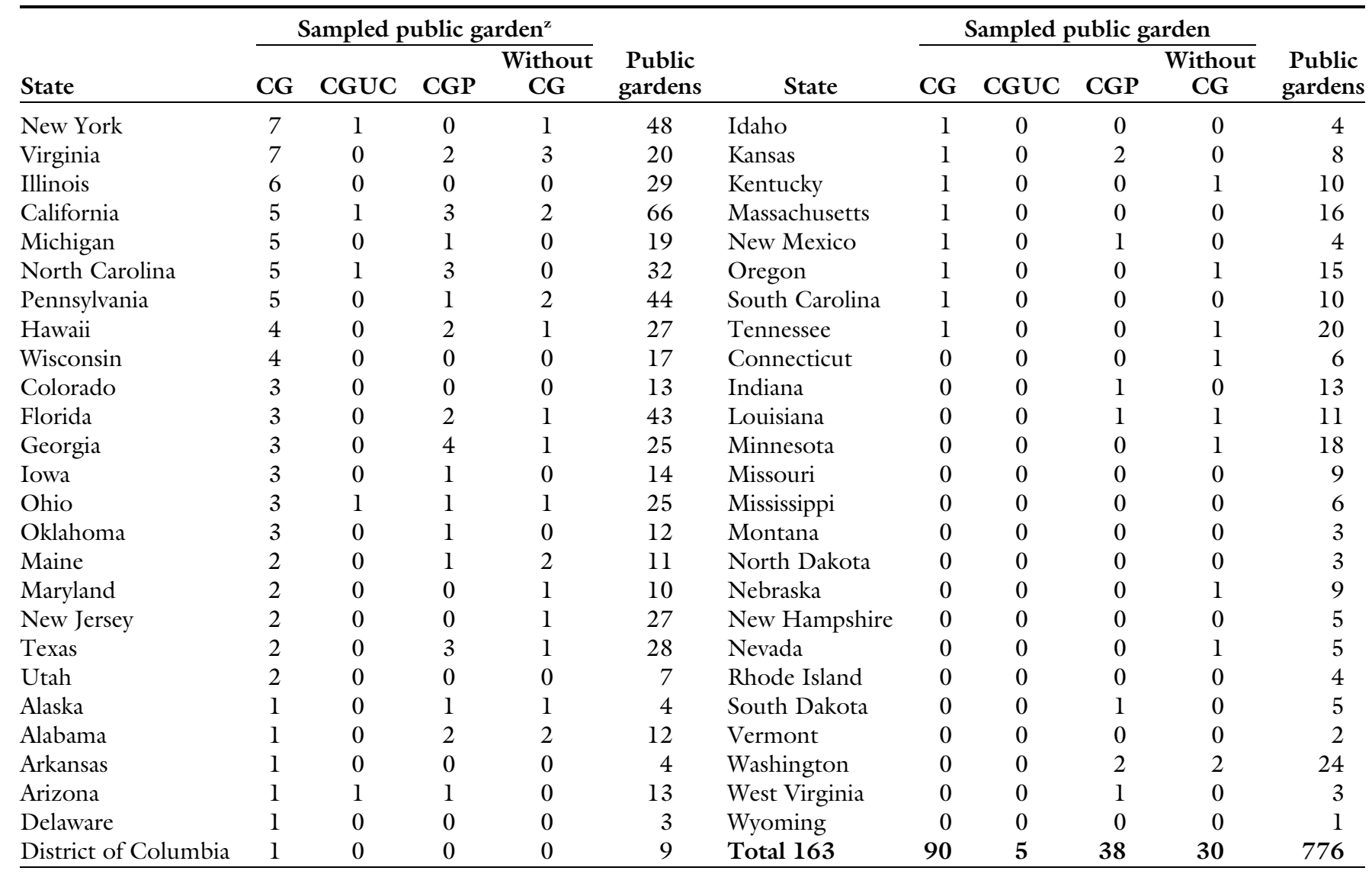

${ }^{2} \mathrm{CG}=$ children's garden; CGUC = children's garden under construction; CGP = children's garden planned.

(1998) and Groundspeak (2010). The two Internet search engines used were Google (1998b) and Wikipedia (2001). The two children's gardenrelated literature resources included the book Designing Outdoor Environments for Children (Tai, 2006) and the thesis entitled An Investigation of Interactivity at the Michigan 4-H Children's Garden (Sobaski, 2006).

A list was compiled from the 12 sources and included a total of 776 places that met Rakow's (2011) definition of a public garden (Fig. 1; Table 1), which states that "a public garden is a mission-based institution that maintains collections of plants for the purposes of education, research, conservation, and/or public display. It must have a system for maintaining plant records and professional staff, be open to the public and provide accommodations for access to all people." The public gardens contained in the list were categorized into six different types, as defined by Rakow (2011):

Table 2. Number of U.S. public gardens (PGs) and children's gardens (CGs) within the six categories of PGs.

\begin{tabular}{lccc}
\hline Garden category & PGs [no. (\%)] & CGs [no. (\%)] & Proportion of CG (CG/PG) \\
\hline Botanical gardens & $118(72.4)$ & $71(78.9)$ & 60.2 \\
Arboreta & $29(17.8)$ & $11(12.2)$ & 37.9 \\
Display gardens & $7(4.3)$ & $3(3.3)$ & 42.9 \\
Historic landscapes & $6(3.7)$ & $3(3.3)$ & 50.0 \\
Conservatories & $2(1.2)$ & $2(2.2)$ & 100.0 \\
Zoos & $1(0.6)$ & $0(0.0)$ & 0.0 \\
Total & $163(100)$ & $90(100)$ & \\
\hline
\end{tabular}

arboreta, botanic gardens, conservatories, display gardens, historic landscapes, and zoos.

To investigate the presence of children's gardens within the 776 listed public gardens, an online survey was conducted using Survey Monkey (2011) between July 2011 and Jan. 2012 by sending questionnaires to the education coordinators and horticulture directors at each of the 776 public gardens. In addition, the type of public garden represented by each garden was researched on each garden's website (Table 2). The survey included questions regarding the presence of children's gardens (Fig. 2; Table 1), their purpose (Table 3 ), their year of establishment (Fig. 3), and their size (Fig. 4) (see Supporting File). The size of each public garden and the year of its establishment were verified using each garden's website (Figs. 3 and 4 ). The number of news articles published about children's gardens during 1990 and 2014 was determined by searching the term "children's gardens" in Google (1998a) (Fig. 5). One hundred and sixty responses were collected from public gardens in 43 states. During July and Aug. 2014, a phone survey 
A

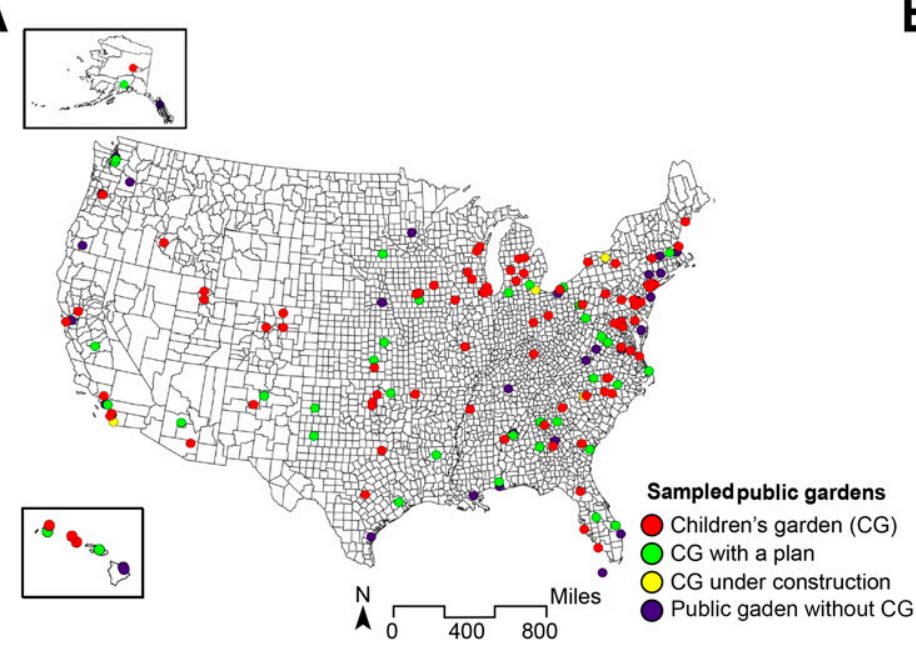

B

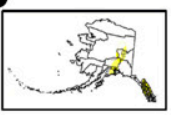

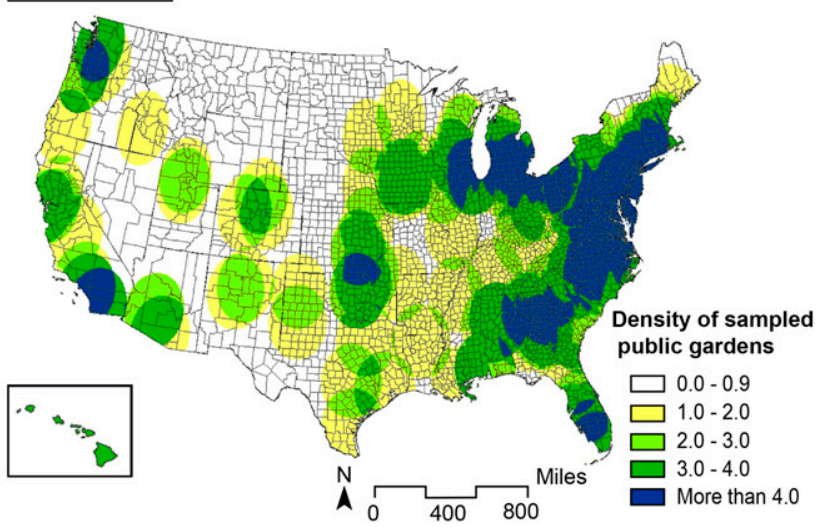

Fig. 2. Map showing the (A) distribution of the public gardens and $(\mathrm{B})$ density of public gardens in the United States; 1 mile = $1.6093 \mathrm{~km}$.

Table 3. Purposes of establishing children's gardens within U.S. public gardens [multiple responses $(n=72)]$.

\begin{tabular}{lc}
\hline Categories & Responses (no.) \\
\hline $\begin{array}{l}\text { To provide an environmental education with the experience } \\
\quad \text { of nature through play in a garden }\end{array}$ & 22 \\
To provide an engaging place for children and families to enjoy & 20 \\
To provide an educational program with hands-on activities & 14 \\
To introduce various plants to children and demonstrate where & 11 \\
$\quad$ food comes from & 10 \\
To attract children and families for garden visits & 11 \\
Others & \\
\hline
\end{tabular}

was performed to reconfirm the information received from the 163 public gardens that had responded to the online survey and to learn whether they were planning to build a children's garden or were currently constructing one. The data were also examined through discussions, interviews and reviews with 17 colleagues across the academic (professor), public (garden director and director of institution), and private (landscape designer, and environmental educator) sectors of public gardening (Table 4).

Data Analysis. Pearson's correlation test was conducted using the overall number of public gardens and the public gardens surveyed in each state to determine the relationship between those surveyed and the total number of public gardens. Using news articles published between 1990 and 2014 retrieved from Google (1998a), a frequency analysis was performed to investigate the presence of children's gardens within public gardens (Table 1), the differences among the six different types of public gardens (Table 2), the number of established public gardens and children's gardens (Fig. 3), the sizes of public gardens and children's gardens according to their ground area (Fig. 4), and the relationship between social interest in children's gardens and their establishment (Fig. 5). In addition, a multiple-response analysis was conducted to determine the purposes of establishing children's gardens within public gardens (Table 3 ).

A $t$ test was performed using data from the 2000 census to determine the factors that influenced the presence of children's gardens within public gardens (Table 5) and the presence of public gardens (Table 6), including local populations, number of children (under 5 years old and 5 to 17 years old), education level (number of people with university degrees or higher), and economic level (per capita income), in the surveyed counties. All statistical analyses were conducted using SPSS (20.0 for Windows; IBM, Armonk, NY).

A spatial analysis technique based on geographic information system (GIS) was employed to analyze the density (Figs. 1A-B and 2B), geographical distribution (Fig. 2A) and area ratio of children's gardens to public gardens in the United States (Fig. 4A). This study projected the location data of public gardens using Albers equal area conic projections after identifying their longitudes and latitudes using addresses. We used the spatial data to analyze the density of public gardens and to map county population density. All of the GIS analyses were conducted using ESRI ArcGIS 10.0 (ESRI, Redlands, CA).

\section{Results and discussion}

Distribution OF PUblic GARDENS. Data on all 776 public gardens collected from the 12 sources described in the "Materials and methods" were used to analyze the density of public gardens and the distribution of county population in the United States. Most public gardens are located in states on the east and west coasts of the United States, including New York (48), Pennsylvania (44), Florida (43), California (66), and Hawaii (27) (Fig. 1; Table $1)$. The counties in the eastern and western states with high population densities have more public gardens at higher densities than do other counties. Counties with relatively low accessibility to public gardens 

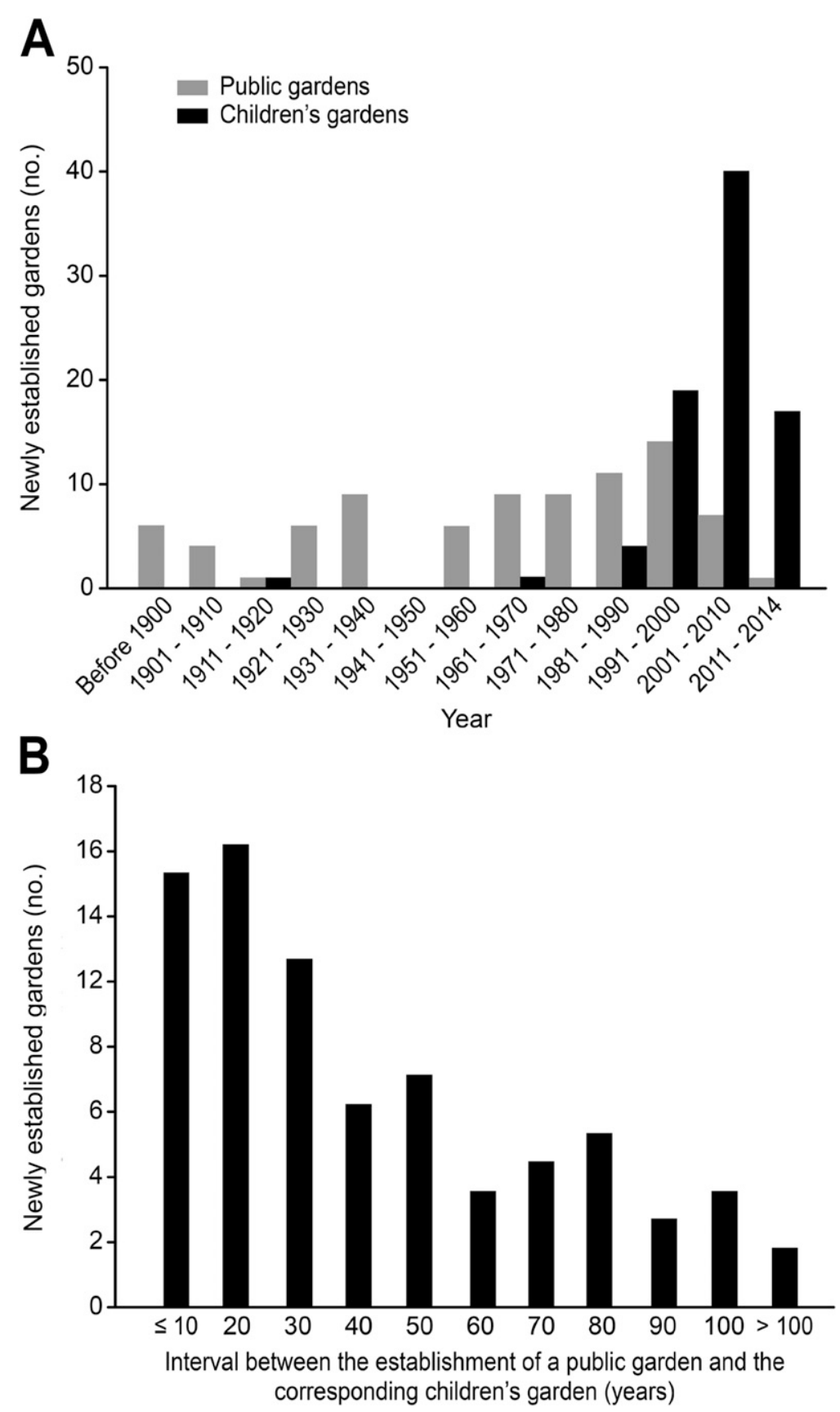

Fig. 3. (A) The number of established public gardens with children's gardens in the United States and of newly established children's gardens in the United States in each time period before 1900 and after 1900 until 2014. (B) The number of years between the opening of the public gardens and the establishment of the associated children's gardens.

were primarily located in the lessdensely populated central United States (Fig. 1). A previous study demonstrated that greater population densities lowered the costs of providing services and resulted in increased public-sector spending (Ladd, 1992).

CurRent status of Children's GARDENS. The 163 surveyed public gardens were primarily located in the eastern and western regions of the country and had similar distribution and densities as the entire list of 776 public gardens (Fig. 2). A Pearson's correlation test that was conducted to verify whether the distribution of the surveyed public gardens correlated to the total distribution of public gardens in the United States showed a statistically significant correlation $(r=0.723$, $P<0.01)$. Therefore, the conclusions drawn from our study may be considered relevant to public gardens across the United States. Among the 163 public gardens that completed the questionnaire, $90(55.2 \%)$ had a children's garden as of 2014. Of the remaining respondents, $5(3.1 \%)$ were currently in the process of building a children's garden, and 38 (23.3\%) were planning to open a children's garden within a few years. The 30 remaining respondents (18.4\%) had no children's gardens (Fig. 2). Taking into account children's gardens under construction and those in the planning phase, the number of public gardens with a children's garden will likely increase in the near future. In addition, the states with the most children's gardens are in the eastern United States, such as New York (7) and Virginia (7), followed by those in the central region, such as Illinois (6) and Michigan (5), and those in the western part of the country, such as California (5) and Hawaii (4) (Table 1).

Categorization of the public gardens into six types shows that the 163 public gardens that were investigated include 118 botanical gardens $(72.4 \%)$, 29 arboreta (17.8\%), 7 display gardens $(4.3 \%), 6$ historic landscapes $(3.7 \%)$, 2 conservatories $(1.2 \%)$, and 1 zoo $(0.6 \%)$. Most of the public gardens with a children's garden are botanical gardens $(78.9 \%)$ and arboreta (12.2\%) (Table 2). This result is similar to that found by Purcell (2010), who showed that botanical gardens accounted for the largest proportion $(50.8 \%)$ of public gardens with adolescent involvement. Although all of the zoos and conservatories investigated through the online survey had children's gardens, these findings were mostly because of a paucity of survey respondents (two or fewer respondents for each). However, $60.2 \%$ of the botanical gardens had children's gardens. As Vergou (2012) notes, historically, managers and developers of botanical gardens have not closely considered the needs of children or adolescents. However, among the factors that encourage botanical garden development, greater attention has been paid in the last 20 years to the value and importance of children and adolescents. This trend implies that among types of public gardens, botanical gardens in particular have developed an interest in establishing children's gardens. According to the definitions of botanical gardens and arboreta (Rakow, 2011), both 


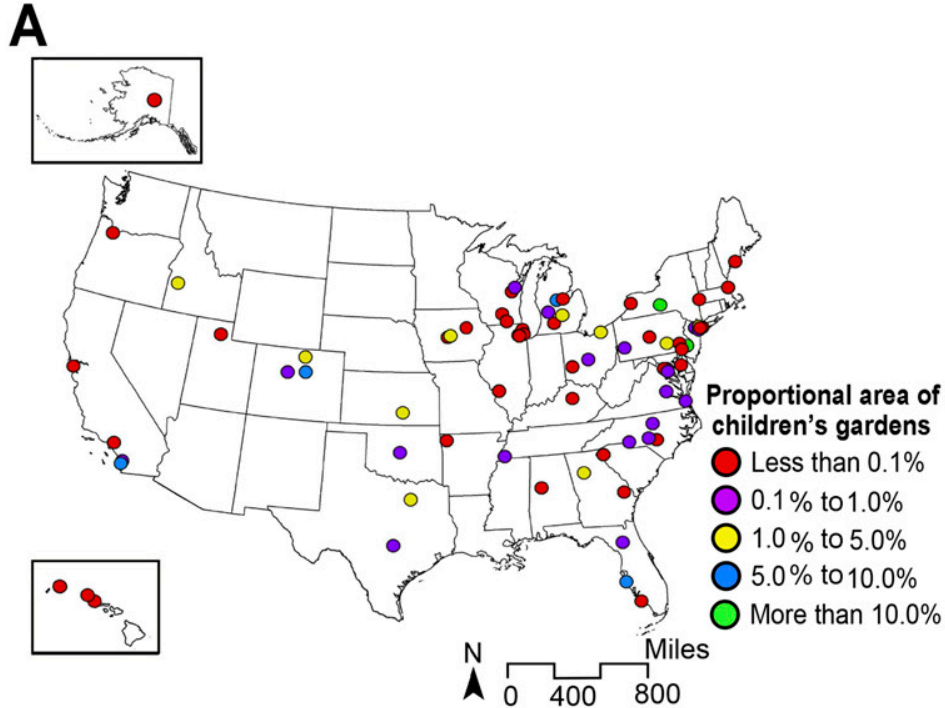

C

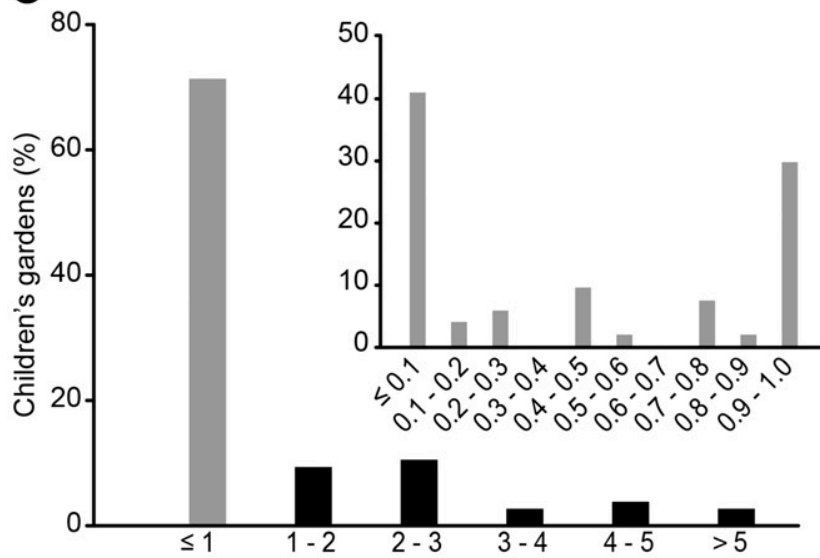

Area of children's gardens in the U.S. (acres)
B

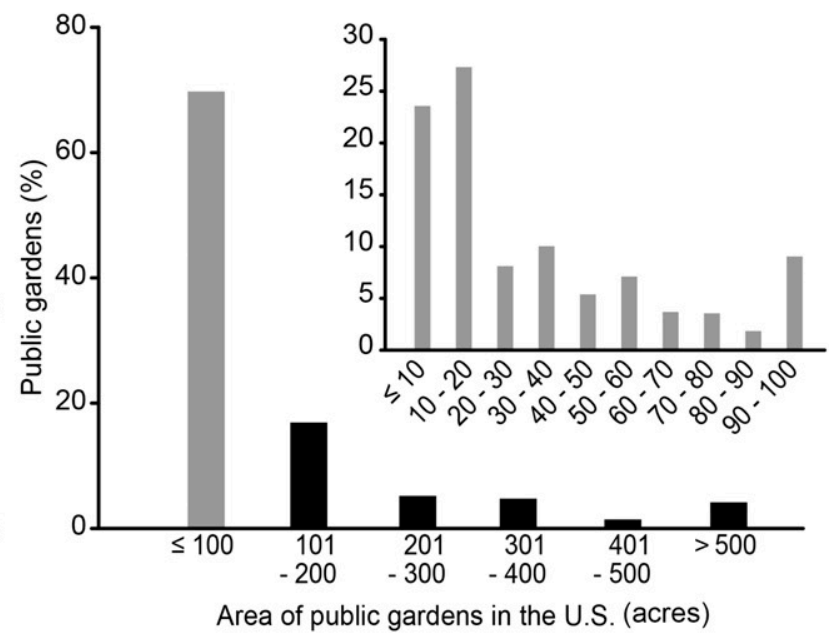

D

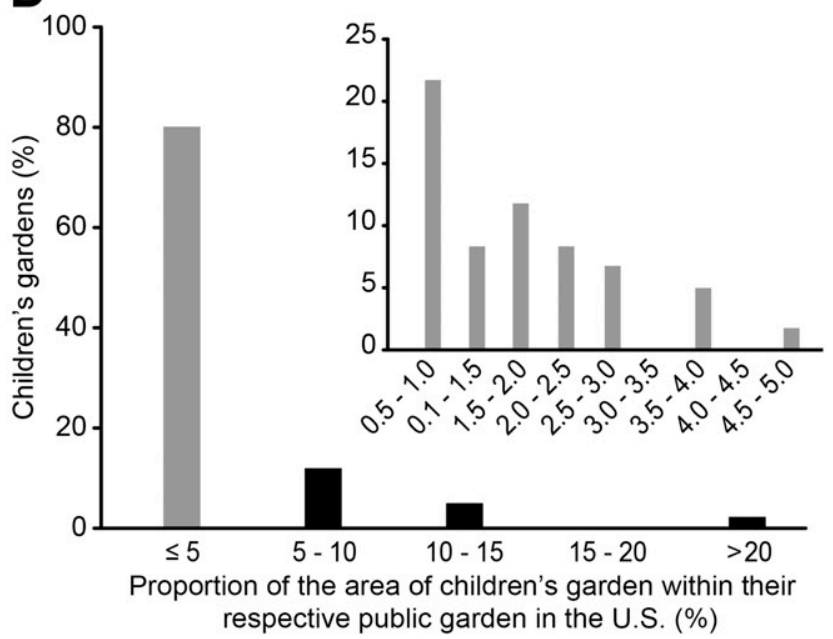

Fig. 4. Geographic distribution of children's gardens in the United States according to the proportion of space they occupy within the public gardens $(A)$. The ground areas of the public gardens $\{\mathrm{B}$ [public gardens $(\%)=($ number of public gardens of $\mathrm{X}$ acres/total number of public gardens) $\times 100]$ (inset $=$ details of public gardens that are $\leq 100$ acres) $\}$ and of the children's gardens $\{\mathrm{C}$ [children's gardens $(\%)=($ number of children's gardens of $\mathrm{X}$ acres/total number of children's gardens $) \times 100]($ inset $=$ details of public gardens that are $\leq 1$ acre) $\}$. The proportion of children's gardens according to their ground area within the public $\{\mathrm{D}$ [children's gardens $(\%)=($ number of children's gardens $/$ number of public gardens $) \times 100$ ] (inset $=$ details of children's gardens that make up $\leq 5 \%$ of the public garden) $\} ; 1$ mile $=1.6093 \mathrm{~km}, 1$ acre $=0.4047$ ha.

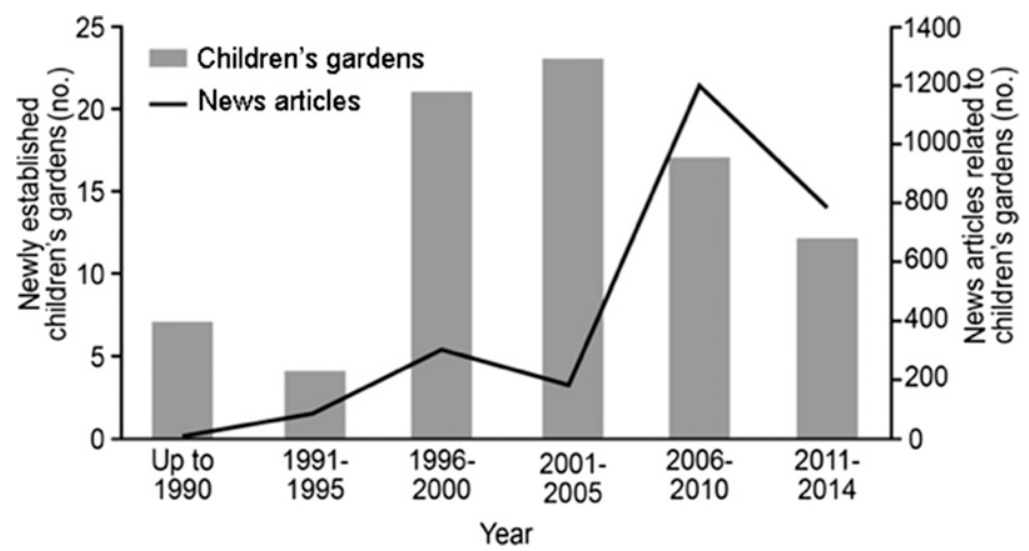

Fig. 5. The number of newly established children's gardens in the United States and the number of children's garden-related news articles published since 1990 in each 5-year time period. The news articles about children's gardens were found via Google (1998a). provide the same public education function, but woody plants are the attraction in arboreta, whereas botanical gardens harbor botanical diversity with both herbaceous and woody plants. Thus, it is implied that the latter provides more diverse educational materials.

Among the surveyed public gardens, the ones with children's gardens report that their main purposes are to provide children with an experience of the natural environment through play as an educational place $(25.0 \%)$, to be an engaging place for families $(22.7 \%)$, and to provide educational programs through experiential 
Table 4. List of respondents from U.S. academic, public, and private sectors of public gardening examined through discussions, interviews, and reviews.

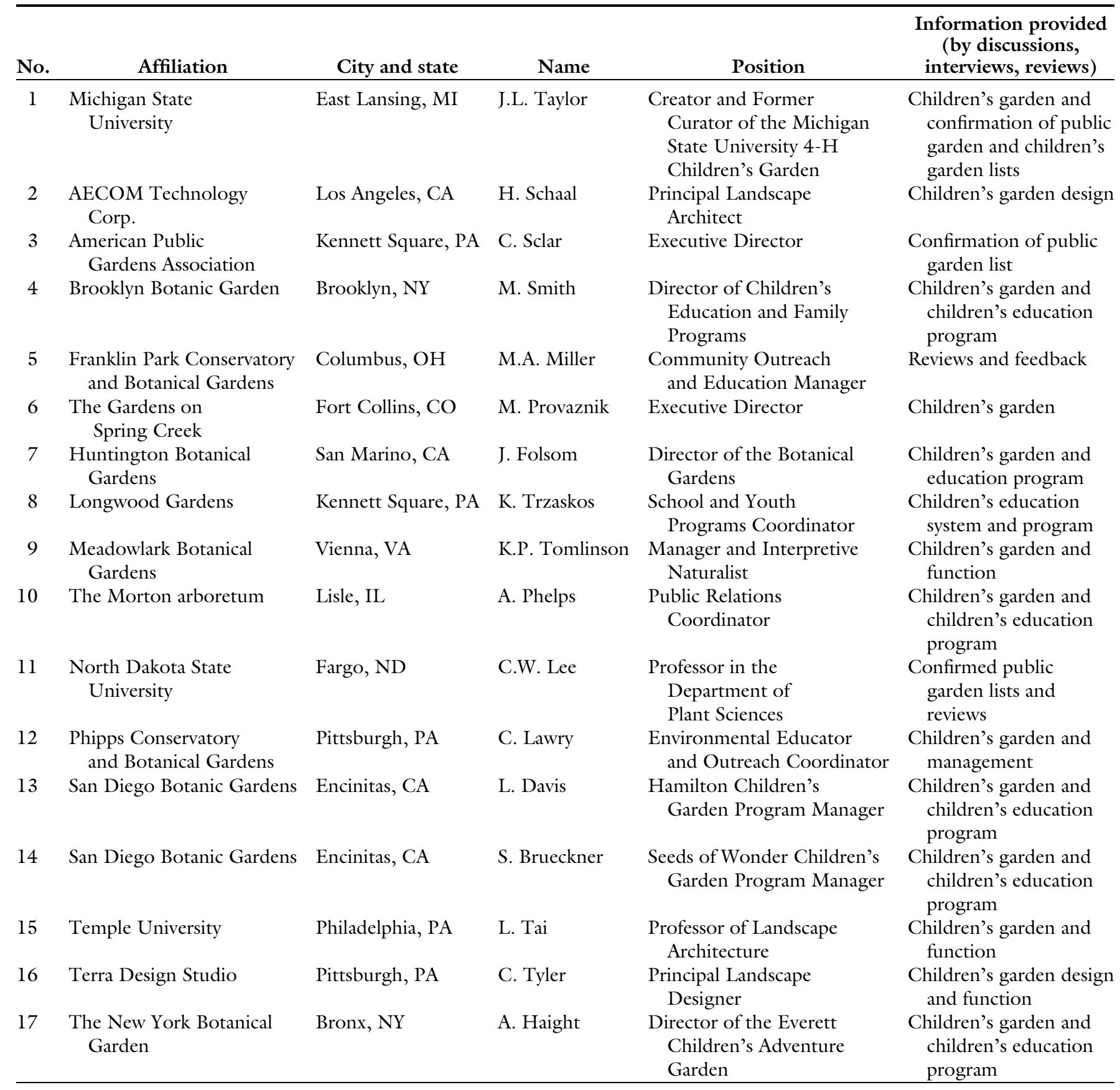

activities (15.9\%). Other reported purposes include providing activities for summer camps to serve children of all physical and mental abilities and encouraging children to eat more vegetables (Table 3 ). This result is similar to the results of previous studies, which reported that the main purpose of establishing children's gardens was to create a space for children to enhance their imagination and dreams by experiencing the natural environment while having fun (DiMare, 2012; Miller, 2005; Sobaski, 2006). The main purpose of children's gardens has not changed; they have focused on providing natural experiences to children for the past decade.

An analysis of the establishment of public gardens and children's gardens considered in this study indicates that the establishment of public gardens largely remained steady until the 1940s, at which time there was a dramatic decrease. After this period, new establishments again stabilized until the 1990s, when there was an increase in the number of new public gardens. In contrast, the increase in the establishment of children's gardens only became widespread from the 1990 s to 2000 and occurred alongside a surge in the establishment of public gardens during the same period.

Although fewer public gardens have been established since 2000 compared with the 1991 to 2000 period, our results show that the number of new children's gardens continued to increase during the same period (Fig. $3 \mathrm{~A})$. This result is in accordance with previous research (Halverson et al., 
Table 5. Relationship between the presence of children's gardens (CGs) within U.S. public gardens at the county level and demographic and socioeconomic factors.

\begin{tabular}{llrrrrc}
\hline Variables & County & $N$ & \multicolumn{1}{c}{ Mean } & \multicolumn{1}{c}{ SD } & $t$ test & $P$ \\
\hline Population & With CG & 82 & $697,089.21$ & $1,255,401.72$ & 1.422 & 0.157 \\
& Without CG & 62 & $462,852.84$ & $699,916.35$ & & \\
Population under & With CG & 82 & $49,202.67$ & $95,403.51$ & 1.321 & 0.189 \\
$\quad$ age 5 years & Without CG & 62 & $32,592.55$ & $54,086.72$ & & \\
Population age 5 & With CG & 82 & $108,176.43$ & $230,726.77$ & 1.167 & 0.246 \\
to 17 years & Without CG & 62 & $73,609.42$ & $119,131.51$ & & \\
Bachelor's degree & With CG & 82 & $98,843.02$ & $167,966.76$ & 1.779 & 0.078 \\
& Without CG & 62 & $59,554.27$ & $94,401.50$ & & \\
Per capita & With CG & 82 & $28,761.01$ & $6,419.53$ & 2.683 & $0.008 * *$ \\
income $(\$)$ & Without CG & 62 & $25,418.63$ & $8,064.86$ & & \\
\hline
\end{tabular}

** Significant at $P<0.01$

Table 6. Relationship between the presence of U.S. public gardens (PGs) at the county level and demographic and socioeconomic factors based.

\begin{tabular}{llrrrrc}
\hline Variables & County & $N$ & \multicolumn{1}{c}{ Mean } & \multicolumn{1}{c}{ SD } & $t$ test & $P$ \\
\hline Population & With PG & 451 & $370,779.40$ & $679,246.05$ & 10.251 & $0.000 * * *$ \\
& Without PG & 2,689 & $42,469.13$ & $84,781.24$ & & \\
Population under & With PG & 451 & $25,651.19$ & $50,989.41$ & 9.494 & $0.000 * * *$ \\
age 5 years & Without PG & 2,689 & $2,828.86$ & $6,008.11$ & & \\
Population age 5 & With PG & 451 & $58,829.46$ & $119,673.14$ & 9.132 & $0.000 * * *$ \\
to 17 years & Without PG & 2,689 & $7,306.77$ & $14,120.42$ & & \\
Bachelor's degree & With PG & 451 & $49,139.78$ & $93,019.24$ & 10.340 & $0.000 * * *$ \\
& Without PG & 2,689 & $3,773.81$ & $13,234.50$ & & \\
Per capita & With PG & 451 & $26,147.11$ & $6,569.09$ & 18.298 & $0.000 * * *$ \\
income $(\$)$ & Without PG & 2,689 & $20,132.99$ & $4,859.61$ & & \\
\hline
\end{tabular}

*** Significant at $P<0.001$.

2008), which found that the timing of children's development was unsurprising as it coincided with increased attention to children's environmental education and physical and cognitive development. In addition, most of the children's gardens located within a public garden were established less than 20 years after the corresponding public garden was established (Fig. 3B).

The proportional area of children's gardens ranged widely, from less than $0.1 \%$ to more than $10.0 \%$, with an average of $4.3 \%(\mathrm{SD}=13.9 \%)$. The children's gardens with the greatest proportional area were primarily located in eastern states, although some were located in central states (Fig. 4A). There were no statistically significant correlations between the sizes of public gardens and children's gardens. A more detailed distribution analysis via a histogram showed that most public gardens were less than 100 acres in size. Of these, most were at the smaller end of the range and were between 0 and 20 acres (Fig. 4B). An analysis of the sizes of children's garden showed a similar trend in that the data were skewed toward the lower end of the range, with a majority of children's gardens being less than 1 acre (Fig. 4C). A histogram of the proportional areas of children's gardens within their public garden (Fig. 4D) showed that these data were also heavily skewed to the smaller end of the range, with most below $5 \%$. Within that range, as the proportional area grew smaller, the number of children's gardens increased, with the majority of children's gardens being less than $1 \%$ of the proportional area of public gardens.

According to the research, children's gardens within botanical gardens are maintained as important spaces (AHS, 2005; Mattern, 1999; Taylor, 1994; Willison and Vergou, 2012). However, because there are large variations in the size of children's gardens and the proportions of children's gardens within public gardens, the area of a children's garden does not seem to indicate its importance to the public garden. Thus, a better measure of the "importance" of the children's garden to the public garden may be each public garden's investment, both financial and programmatic, in its children's garden. Therefore, further related studies are needed.

To investigate the social interest in children's gardens over time, the number of news articles published about children's gardens was compared with the number of newly established children's gardens by year. Yearly data were collected beginning in the early 1990s because the number of children's gardens within public gardens began to increase in popularity at that time. The number of newly established children's gardens increased between the years of 1996 and 2005 and then decreased. Interestingly, the number of news articles about children's gardens dramatically increased between 2006 and 2010 (Fig. 5). This increase in the number of published articles about children's gardens would have been an effective way to inform the public about these new gardens and possibly to increase public interest.

The results of $t$ tests in analyses relating demographic and socioeconomic factors to children's gardens showed that only per capita income $(P<$ 0.01 ) had positive correlations with children's gardens; correlations with other factors did not reach statistical significance. This result is in accordance with previous reports that personal income influences the use of public services, such as park and recreation services (Scott and Jackson, 1996; Scott and Munson, 1994). On average, counties with children's gardens showed larger populations, more preschoolers and school children, and higher levels of education and personal income than counties without children's gardens did (Table 5). Similar results were found for 776 public gardens, which were significantly correlated with all of the examined demographic and socioeconomic factors (Table 6). It was found that the population, education level, and personal income level of each county affected the development of children's gardens and public gardens. There is a perception that gardens are primarily enjoyed by elite, middle-class people (Dodd and Jones, 2010). This perception may reflect the more common presence of children's gardens and public gardens in 
counties related to socioeconomic perspective.

\section{Conclusions}

The current status of public gardens and children's gardens in the United States was investigated in this study. Information obtained from online surveys and census data were used to characterize the distribution and development of children's gardens using spatial analysis and mapping methods. Our results indicate that children's gardens are nearly evenly distributed among public gardens, but the density is greater on the east and west coasts. Most children's gardens were planned and established after the associated public garden was created. It is expected that the number of children's gardens within public gardens in the United States will increase in the near future. However, based on the trends observed in this study, it is expected that fewer public gardens will be built in the United States. It is anticipated that children's gardens will continue to be built in the private sector and in public places, such as community gardens, hospitals, and schools, to meet the rising demand for them (Birky, 2009; Waliczek et al., 2000; Whitehouse et al., 2001). From a demographic and socioeconomic perspective, counties with larger populations, higher educational levels and higher income will contain more children's gardens.

According to the results of the online survey, children's gardens serve as multifunctional places for urban children. They are spaces where children may visit with their families, enjoy and rest in a natural setting, or find an educational place to experience and explore nature as urbanization increases. The findings of this study may not represent the true status of children's and public gardens because the data collection was primarily conducted using Internet searches and online surveys, which may have missed vital information. Further studies are needed to incorporate possible missing information and to better describe the status of children's gardens, which are influenced by various socioeconomic and environmental factors.

With renewed public interest, the growth of children's gardens in public areas is likely to continue. Further investigation is needed to characterize the changing status and role of children's gardens and related activities at various public horticulture establishments in the United States.

\section{Literature cited}

American Horticultural Society. 2005. Youth Gardening. 10 Oct. 2010. <http://www. ahs.org/youth_gardening/index.htm>.

American Horticultural Society. 2010. Garden Directory. Reciprocal Admissions Program Participants. 10 Oct. 2010. <http://www.ahs.org/gardeningprograms $/ \mathrm{rap} /$ find $>$.

American Public Gardens Association. 2010. Membership Directory. 10 Oct. 2010. <http://publicgardens.org/ content/membership-central-0 $>$.

Birky, J. 2009. The modern community garden movement in the United States: Its roots, its current condition and its prospects for the future. MS Thesis, Univ. South Florida, Tampa.

Botanic Gardens Conservation International. 2010. Garden Search: United States of America. 10 Oct. 2010. <http:// www.bgci.org/garden_search.php>.

Cherney, I.D. and K. London. 2006. Gender-linked differences in the toys, television shows, computer games, and outdoor activities of 5-to 13-year-old children. Sex Roles 54:717-726.

Children's Garden Network. 2011. CGN Garden Directory. 10 Jan. 2011. <http://www.childrensgardennetwork. org/index . cfm/fuseaction/ gardenDirectory.main/index.htm>.

Connell, J. 2004. The purest of human pleasures: The characteristics and motivations of garden visitors in Great Britain. Tourism Mgt. 25:229-247.

Connell, J. 2005. Managing gardens for visitors in Great Britain: A story of continuity and change. Tourism Mgt. 26:185-201.

Cooper-Marcus, C. and M. Barnes. 1995. Gardens in healthcare facilities: Uses, therapeutic benefits, and design recommendations. Ctr. Health Design, Univ. California, Berkeley.

DiMare, J.A. 2012. An exploration of place-based design in northeastern children's gardens. MS Thesis, Cornell Univ., Ithaca, NY.

Dodd, J. and C. Jones. 2010. Redefining the role of botanic gardens: Towards a new social purpose. Botanic Gardens Conservation Intl., Surrey, UK.

Eberbach, C. 1988. Garden design for children. MS Thesis, Univ. Delaware, Newark.
Falk, J.H. 1998. A framework for diversifying museum audiences. Museum News 77:36-39, 61.

Goddard, M.A., A.J. Dougill, and T.G. Benton. 2010. Scaling up from gardens: Biodiversity in conservation in urban environments. Trends Ecol. Evol. 25:90-98.

Google. 1998a. Google News Archives Search. 10 Oct. 2010. <https://news. google.com/news/advanced_news_. search?as_drrb=a>.

Google. 1998b. Google Search. 10 Oct. 2010. <https://www.google.com>.

Groundspeak. 2010. Waymarking.com search. 10 Oct. 2010. <http://www. waymarking.com/wm/search.aspx? $\mathrm{f}=1 \& \mathrm{kw}=$ children's\%20 gardens \&st=2>.

Halverson, A., N. Wells, D. Rakow, and S. Skelly. 2008. The growth of children's gardens, p. 7-35. In: E. Goodenough (ed.). A place for play: A company volume to the Michigan television film "Where do the children play?" Natl. Inst. Play, Carmel Valley, CA.

Hawks, S. 1991. Recreation in the family, p. 387-433. In: S.J. Bahr (ed.). Family research: A sixty year review, 1930-1990. Lexington Books, New York, NY.

Hoffman, A.M. 2008. Alternative interpretive strategies for multi-generational learning in public horticulture institutions. MS Thesis, Univ. Delaware, Newark.

Holder, M.D., B. Coleman, and Z.L. Sehn. 2009. The contribution of active and passive leisure to children's well-being. J. Health Psychol. 14:378-386.

Kaplan, R. and S. Kaplan. 1989. The experience of nature: A psychological perspective. Cambridge Univ. Press, New York, NY.

Ladd, H.F. 1992. Population growth, density and the costs of providing public services. Urban Stud. 29:273-295.

Lee, A.C. and R. Maheswaran. 2011. The health benefits of urban green spaces: A review of the evidence. J. Public Health (Oxf.) 33:212-222.

Leisure Market Research Handbook. 2012. The 2012-2013 leisure market research handbook. Richard K. Miller Assoc., Atlanta, GA.

Lewis, C.A. 1992. Effects of plants and gardening in increasing interpersonal and community well-being, p. 55-65. In: D. Relf (ed.). The role of horticulture in human well-being and social development: A national symposium. Timber Press, Portland, OR.

Lewis, C.A. 1996. Green nature/human nature: The meaning of plants in our lives. Univ. Illinois Press, Urbana, IL. 
Louv, R. 2008. Last child in the woods: Saving our children from nature-deficit disorder. 2nd ed. Algonquin Books, Workman, NC.

Maller, C. and M. Townsend. 2006. Children's mental health and wellbeing and hands-on contact with nature: Perceptions of principals and teachers. Intl. J. Learning 12:359-372.

McMichael, A.J. 2001. Human frontiers, environments and disease: Past patterns, uncertain futures. Cambridge Univ. Press, Cambridge, UK.

Mattern, V. 1999. Reinventing the children's garden. Public Garden 14:3-7.

Miller, A.L. 2010. Children's gardens: Design, participation, and behavior for environmental competence. MS Thesis, Cornell Univ., Ithaca, NY.

Miller, M.A. 2005. An exploration of children's garden: Reported benefits, recommended elements, and preferred visitor autonomy. PhD Diss., Ohio State Univ., Columbus.

Mithal, A., D.A. Wahl, J.P. Bonjour, P. Burckhardt, B. Dawson-Hughes, J.A. Eisman, G. El-Hajj Fuleihan, R.G. Josse, and J. Morales-Torres International Osteoporosis Foundation Committee of Scientific Advisors Nutrition Working Group. 2009. Global vitamin D status and determinants of hypovitaminosis D. Osteoporos. Intl. 20:1807-1820.

Moore, R. and H. Wong. 1997. Natural learning: The life history of an environmental schoolyard. MIG Commun., Berkeley, CA.

Morton Arboretum. 2011. Full Morton register of arboreta. 15 Apr. 2011. <http://www.arbnet.org/component/ mtree/new.html>.

Nabhan, G.P. and S. Trimble. 1994. The geography of childhood: Why children need wild places. Beacon Press, Boston, MA.

National Gardening Association. 2010. Public gardens locator. 10 Oct. 2010. <http://www.garden.org/public gardens $/>$.

Nightingale Garden Company. 1998. Gardenvisit.com: Gardens in the USA. 10 Jan. 2010. <http://www.gardenvisit. com/gardens/in/usa>.

Perrin, J.M., S.R. Bloom, and S.L. Gortmaker. 2007. The increase of childhood chronic conditions in the United States. J. Amer. Medical Assn. 297:2755-2759.

Pretty, J., J. Peacock, M. Sellens, and M. Griffin. 2005. The mental and physical health outcomes of green exercise. Intl. J. Environ. Health Res. 15:319-337.

Purcell, K. 2010. An analysis of adolescent involvement at public horticulture institutions. MS Thesis, Univ. Delaware, Newark.

Rakow, D. 2011. What is a public garden? Public Garden 26:7-12.

Robertson, I.M. 1996. Botanical gardens in the contemporary world. Public Garden 11:16-21.

Scott, D. and E.L. Jackson. 1996. Factors that limit and strategies that might encourage people's use of public parks. J. Park Recreation Administration 14:1-17.

Scott, D. and W. Munson. 1994. Perceived constraints to park usage among individuals with low incomes. J. Park Recreatation Administration 12:52-69.

Shair, G. 1999. A history of children's gardens. Public Garden 14:9-11.

Shaw, S.M. and D. Dawn. 2001. Purposive leisure: Examining parental discourses on family activities. Leisure Sci. 23:217-231.

Sherer, D.M. 2006. The benefits of parks: Why America needs more city parks and open space. Trust for Public Land, San Francisco, CA.

Sobaski, C. 2006. An investigation of interactivity at the Michigan 4-H Children's Garden. MS Thesis, Univ. Delaware, Newark.

Stenvall, E. 2009. Sellaist ihan tavallist arkee. Edita Prima Oy, Helsinki, Finland.

Stone, D.M. 1984. Children's gardening at BBG. Plants Garden 40:6-10.

Survey Monkey. 2011. Survey Monkey. 17 July 2011 . <http://www . surveymonkey.com>.

Tai, L. 2006. Designing outdoor environments for children. McGraw Hill, New York, NY.

Taylor, A.F. and F.E. Kuo. 2009. Children with attention deficits concentrate better after walk in the park. J. Atten. Disord. 12:402-409.

Taylor, A.F., A. Wiley, F.E. Kuo, and W.C. Sullivan. 2001. Coping with ADD:
The surprising connection to green play settings. Environ. Behav. 33:54-77.

Taylor, J. 1994. In a child's garden... imagination grows. Amer. Hort. 7:24-26.

Trelstad, B. 1997. Little machines in their gardens: A history of school gardens in America, 1891 to 1920. Landscape J. 16:161-173.

Ulrich, R.S. 1999. Effects of gardens on health outcomes: Theory and research, p. 27-86. In: C. Cooper Marcus and M. Barnes (eds.). Healing gardens. Therapeutic benefits and design recommendations, Wiley, New York, NY.

United Nations. 2014. World urbanization prospects. 10 Sept. 2014. <http:// esa.un.org/unpd/wup/Highlights/ WUP2014-Highlights.pdf $>$.

U.S. Census Bureau. 1990. Census of population and housing. U.S. Census Bur., Washington, DC. 10 Aug. 2014. <http://www.census.gov/prod/www/ decennial.html $>$.

U.S. Census Bureau. 2010. Urban, urbanized area, urban cluster, and rural population, 2010 and 2000: United States. U.S. Census Bur., Washington, DC. 21 July 2014. <http://www.census. gov/geo/reference/ua/urban-rural2010.html>.

Vergou, A. 2012. Child's eye view: Changing perspectives on botanic gardens in the modern roots. Botanic Garden Conservation Intl. Educ. Rev. 9:2-5.

Waliczek, T.M., R.D. Lineberger, J.M. Zajicek, and J.C. Bradley. 2000. Using a web-based survey to research the benefits of children's gardening. HortTechnology 10:71-76.

Whitehouse, S., J.W. Varni, M. Seid, C. Cooper-Marcus, M.J. Ensberg, J.R. Jacobs, and R.S. Mehlenbeck. 2001. Evaluating a children's hospital garden environment: Utilization and consumer satisfaction. J. Environ. Psychol. 21:301314.

Wikipedia. 2001. List of botanical gardens and arboretums in the United States. 10 Oct. 2010. <https://en.wikipedia.org/ wiki/List_of_botanical_gardens_and_ arboretums_in_the_United_States $>$.

Willison, J. and A. Vergou. 2012. Roots: Children's gardens. Botanic Garden Conservation Intl. Educ. Rev. 9:1-39. 